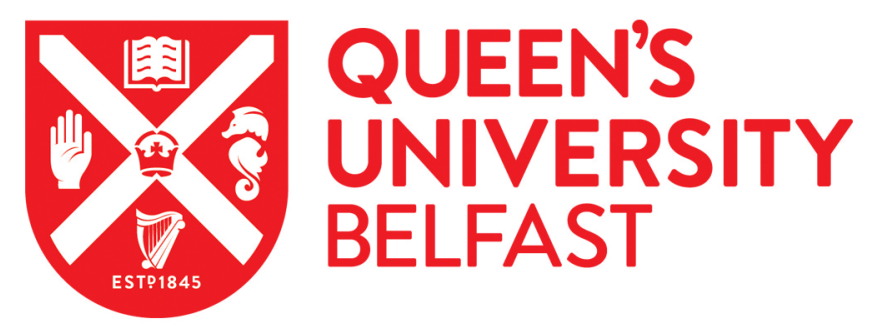

\title{
Batch to Continuous Photocatalytic Degradation of Phenol using TiO2 and Au-Pd nanoparticles supported on TiO2
}

\author{
Yilleng, M. T., Gimba, E. C., Ndukwe, G. I., Bugaje, I. M., Rooney, D. W., \& Manyar, H. G. (2018). Batch to \\ Continuous Photocatalytic Degradation of Phenol using TiO2 and Au-Pd nanoparticles supported on TiO2. \\ Journal of Environmental Chemical Engineering, 6(5), 6382-6389. https://doi.org/10.1016/j.jece.2018.09.048
}

Published in:

Journal of Environmental Chemical Engineering

Document Version:

Peer reviewed version

Queen's University Belfast - Research Portal:

Link to publication record in Queen's University Belfast Research Portal

\section{Publisher rights}

Copyright 2018 Elsevier

This manuscript is distributed under a Creative Commons Attribution-NonCommercial-NoDerivs License

(https://creativecommons.org/licenses/by-nc-nd/4.0/), which permits distribution and reproduction for non-commercial purposes, provided the author and source are cited.

\section{General rights}

Copyright for the publications made accessible via the Queen's University Belfast Research Portal is retained by the author(s) and / or other copyright owners and it is a condition of accessing these publications that users recognise and abide by the legal requirements associated with these rights.

Take down policy

The Research Portal is Queen's institutional repository that provides access to Queen's research output. Every effort has been made to ensure that content in the Research Portal does not infringe any person's rights, or applicable UK laws. If you discover content in the Research Portal that you believe breaches copyright or violates any law, please contact openaccess@qub.ac.uk. 


\section{Batch to Continuous Photocatalytic Degradation}

\section{of Phenol using $\mathrm{TiO}_{2}$ and Au-Pd nanoparticles}

\section{supported on $\mathrm{TiO}_{2}$}

Moses T. Yilleng, ${ }^{\$ \S}$ Emmanuel C. Gimba,${ }^{\dagger}$ George I. Ndukwe,${ }^{\dagger}$ Idris M. Bugaje, ${ }^{\S}$ David W.

$$
\text { Rooney and Haresh G. Manyar*, }
$$

$\$$ Theoretical and Applied Catalysis Research Cluster, School of Chemistry and Chemical Engineering, Queen's University Belfast, David-Keir Building, Stranmillis Road, Belfast, BT9

$$
5 \mathrm{AG}, \mathrm{UK}
$$

${ }^{\dagger}$ Department of Chemistry, Ahmadu Bello University, Zaria Nigeria

${ }^{\S}$ National Research Institute for chemical Technology, Zaria Nigeria

\section{*Corresponding Author}

Haresh G. Manyar

Email: h.manyar@qub.ac.uk

Phone: +442890976608

Fax: + 442890974687 
KEY WORDS: Visible light photocatalyst, $\mathrm{Au} / \mathrm{TiO}_{2}, \mathrm{Pd} / \mathrm{TiO}_{2}$, Continuous Taylor flow reactor, Photocatalytic degradation, Phenol

ABSTRACT: A series of $\mathrm{Au}-\mathrm{Pd} / \mathrm{TiO}_{2}$ catalysts were synthesized in different weight $\%$ using sol-immobilization method. Of the range studied $1 \% \mathrm{Pd} / \mathrm{TiO}_{2}$ catalyst achieved $86.4 \%$ conversion of phenol to $\mathrm{CO}_{2}$ in a standard batch-slurry system utilizing UV. However under recycle or continuous operation Pd leaching from catalyst surface led to gradual deactivation. Au-Pd nanoparticles supported on $\mathrm{TiO}_{2} \mathrm{P} 25$ were stable and recyclable, here Au species were found to help to anchor Pd species on $\mathrm{TiO}_{2}$, and no observable Pd leaching occurred. Utilizing UV, $1 \% \mathrm{Pd} / \mathrm{TiO}_{2}$ showed faster rate of phenol degradation in comparison to $\mathrm{Au}-\mathrm{Pd} / \mathrm{TiO}_{2}$, while $1 \% \mathrm{Au} / \mathrm{TiO}_{2}$ and $0.5 \% \mathrm{Au}-0.5 \% \mathrm{Pd} / \mathrm{TiO}_{2}$ showed faster phenol degradation rates under visible light. The $\mathrm{TiO}_{2}$ P25 support was also found to be active, stable and recyclable in phenol degradation utilizing UV; and was hence considered suitable for continuous operation. However poor oxygen mass transfer led to the formation and lay-down of polymeric species when using a Trickle bed approach. Operation in the Taylor flow regime was demonstrated to increase oxygen saturation and significantly reduced deactivation. Hence continuous photocatalytic degradation of phenol could be achieved using $\mathrm{TiO}_{2}$ under Taylor Flow conditions.

\section{Introduction}

The synergistic and promotional effect of $\mathrm{Au}$ in $\mathrm{Au}-\mathrm{Pd}$ catalysts has been widely reported in the past decade [1-4]. Within these studies, the superior activities of $\mathrm{Au}-\mathrm{Pd}$ bimetallic catalysts, than monometallic Pd or Au catalysts, have been attributed to both ligand and ensemble effects $[5,6]$. It is considered that noble metals supported on $\mathrm{TiO}_{2}$ surface promote the space-charge separation of photo-excited electron-hole pairs and suppress the charge recombination, resulting 
in longer life-time of holes in $\mathrm{TiO}_{2}$ valence band, thus enhancing the photocatalytic activity of $\mathrm{TiO}_{2}$. Recently, the photocatalytic degradation of phenolics using Au-Pd based catalysts has received considerable attention $[7,8]$. Su et al. showed enhancement of photocatalytic activity of $\mathrm{Au}-\mathrm{Pd} / \mathrm{TiO}_{2}$ catalysts over pristine $\mathrm{TiO}_{2}$, wherein the metal nanoparticles are strongly involved in the reaction mechanism by suppressing undesired redox reactions. In photocatalysis, $\mathrm{TiO}_{2}$ is the most prominent catalyst used in oxidation processes as it promotes the production of hydroxyl radicals which, through charge transfer and secondary radical formation processes, lead to the oxidation/reduction of organics in aqueous systems. $\mathrm{TiO}_{2}$ 's ability to oxidize organic compounds under UV has led to such materials being applied in waste/contaminated water treatments.

Photocatalytic oxidation of phenolics utilizing UV is affected by solution concentration, $\mathrm{pH}$, quantity, morphology and nature of the metal oxides present in the catalyst [9-12]. Besides, these factors, the reactor design must be optimized in order to assure complete degradation of organics [13]. Scaling up photocatalytic reactors is, however, a complex process with many factors needing consideration to yield a technically and economically viable process. These factors include distribution of pollutant and photocatalyst, pollutant/oxygen mass transfer, reaction kinetics, and irradiation characteristics [14].

While the current literature focuses on slurry systems using gas sparging and continuous mixing; these can lead to down-stream problems in the catalyst recovery and filtration stages. Within industry fixed bed multi-phase reactors e.g. trickle beds, are often used to mitigate this catalyst separation problem however given the large bed diameters illumination can be problematic when considering them for photocatalysis [15]. However small scale fixed bed reactors can be used for such processes. It is also known that multi-phase fixed bed reactors can 
be operated under different gas and liquid flow regimes which in turn present different flow characteristics in the bed. Trickle flow is associated with a continuous co/counter-current flow of both the liquid and gas through the bed. Alternatively in Taylor flow the liquid and gas flow as separate slugs. Depending on the demands of the catalyst either of these two flow regimes, or others available, could be the most suitable.

Herein, this paper reports the heterogeneous photocatalytic degradation of Phenol using two different reactor types (suspension/slurry batch, and fixed-bed) with the latter operating in either trickle or Taylor flow) using $\mathrm{Au}-\mathrm{Pd} / \mathrm{TiO}_{2} \mathrm{P} 25$ and $\mathrm{TiO}_{2} \mathrm{P} 25$ catalysts. Such designs were used to develop a greater understanding of the processes involved and to enhance the availability of oxygen. Using such approaches the reactor can be continuously operated (herein for a period of three days).

\section{Experimental Section}

\subsection{Materials}

All reagents were of analytical grade. Palladium Chloride, Gold Tetrachloroaurate, Poly Vinyl Alcohol $(\mathrm{MW}=10,000 ; 80 \%$ hydrolyzed $)$ and methanol (HPLC grade) were obtained from Sigma Aldrich UK, $\mathrm{TiO}_{2} \mathrm{P} 25$ was obtained from Degussa (Evonik). Oxygen gas (99.5\% Purity) was obtained from BOC UK.

\subsection{Preparation of $\mathrm{Au} / \mathrm{TiO}_{2}, \mathrm{Pd} / \mathrm{TiO}_{2}$ and $\mathrm{Au}-\mathrm{Pd} / \mathrm{TiO} \mathrm{O}_{2}$ catalysts}

The metal nanoparticles ( $\mathrm{Au}, \mathrm{Pd}, \mathrm{Au}-\mathrm{Pd}$ ) supported on $\mathrm{TiO}_{2}$ catalysts were prepared by using a modified sol immobilization method reported by $\mathrm{Su}$ et al [8]. To an aqueous $\mathrm{PdCl}_{2}$ and $\mathrm{HAuCl}_{4}$ solution, $1 \mathrm{wt} \%$ PVA solution was added as a protective ligand $[\mathrm{PVA} /(\mathrm{Au} \& \mathrm{Pd}) \mathrm{w} / \mathrm{w}=1.2]$. A freshly prepared $0.1 \mathrm{M} \mathrm{NaBH}_{4}$ solution $\left[\mathrm{NaBH}_{4} /(\mathrm{Au} \& \mathrm{Pd})(\mathrm{mol} / \mathrm{mol})=5\right]$ was then added to 
form a dark brown sol. After $30 \mathrm{~min}$, the colloid was immobilized by adding $\mathrm{TiO}_{2}$ (acidified to pH 1-2 by sulfuric acid) under vigorous stirring for $2 \mathrm{~h}$. The catalyst was filtered, washed with distilled deionised water, dried at $120^{\circ} \mathrm{C}$ overnight and calcined in air for $4 \mathrm{hrs}$ at $500{ }^{\circ} \mathrm{C}$.

\subsection{Characterization}

UV-Vis absorption spectra were recorded using Perkin Elmer Lambda 6505 spectrophotometer in the range of $250-800 \mathrm{~nm}$ at a scanning speed of $300 \mathrm{~nm} \mathrm{~min}^{-1}$. Structural characterization was performed using X-ray diffraction measurements using $\mathrm{Cu} \mathrm{K}_{\alpha}$ radiation $(1.5405 \AA)$ on a PANalytical X'PERT PRO MPD diffractometer equipped with reflection geometry, a NaI scintillation counter, a curved graphite crystal monochromator and a nickel filter. The scattered intensities were collected from $5^{\circ}$ to $80^{\circ}(2 \theta)$ by scanning at $0.017^{\circ}(2 \theta)$ steps with a counting time of $0.5 \mathrm{~s}$ at each step. The Au and Pd content of the fresh and used catalysts was determined by ICP-OES metal analysis using Perkin- Elmer, P-1000 Spectrometer. The surface area, total pore volume and average pore diameter were measured by $\mathrm{N}_{2}$ sorption isotherms at 77K using Micromeritics ASAP 2020.

\subsection{Measurement of photocatalytic activity}

Photocatalytic activity was evaluated using phenol degradation. The reactors used were closed Pyrex reactors with a diameter of $42.7 \mathrm{~mm}$ and a height of $210 \mathrm{~mm} .100 \mathrm{~mL}$ of a solution containing $94.11 \mathrm{mg} / \mathrm{L}(1 \mathrm{mMol})$ of phenol in deionized water and $0.3 \mathrm{~g}$ of the catalyst was added to the reactor. The $\mathrm{pH}$ of the aqueous phenol solution was monitored during the reaction. The suspension was stirred at $650 \mathrm{rpm}$ at ambient temperature for $2 \mathrm{hrs}$ in the dark, and an aliquot was withdrawn to analyze equilibrium phenol concentration. The mixture was then exposed to UV light using a Rayonet RMR-600 reactor equipped with 6 (8 Watt) UV lamps (350nm wavelength), with an arc length of $76.2 \mathrm{~mm}$ each. (Figure S1, supporting information). An 
oxygen balloon was connected to the reactor in order to assure a high oxygen saturation of the solution. At regular time intervals aliquots were withdrawn for HPLC analysis.

Photocatalytic activity of the prepared catalysts was also evaluated using a tubular trickle bed column reactor. Typical reactor set up to operate under the Taylor flow regime, is shown in Figure 1. This reactor consisted of a quartz glass tube having an external diameter of $6 \mathrm{~mm}$ and an internal diameter of $4 \mathrm{~mm}$. Reagents were pumped to the reactor bed at a flow rate of $3 \mathrm{ml}$ $\min ^{-1}$. A second peristaltic pump connected to the phenol solution reservoir pumped fresh solution into the reservoir at a flow rate of $0.083 \mathrm{ml} \mathrm{min}^{-1}$. Using this approach the reactor operated continuously in a recycle mode i.e. recirculation of the reagents to the reactor with continuous make up of fresh reagent. In each experiment a batch of $300 \mathrm{~mL}$ containing 94.1 $\mathrm{mg} / \mathrm{L}(1 \mathrm{mMol})$ phenol in water was treated over a period of 92 hours. $1.0 \mathrm{~g}$ of a Pd, $\mathrm{Au}$, and Pd$\mathrm{Au} / \mathrm{TiO}_{2}$ was pelletized and sieved to the $456-600 \mu \mathrm{m}$ size range. At regular time intervals, aliquotes were withdrawn for HPLC analysis. HPLC analysis was performed using Agilent 1100 system equipped with Eclipse XDB-C18 reverse phase column $(3.5 \mu \mathrm{m}, 4.6 \times 150 \mathrm{~mm})$ and Diode Array Detector (DAD) at a wavelength of $254 \mathrm{~nm}$ using $50 \%$ methanol and $50 \%$ water as the mobile phase. 


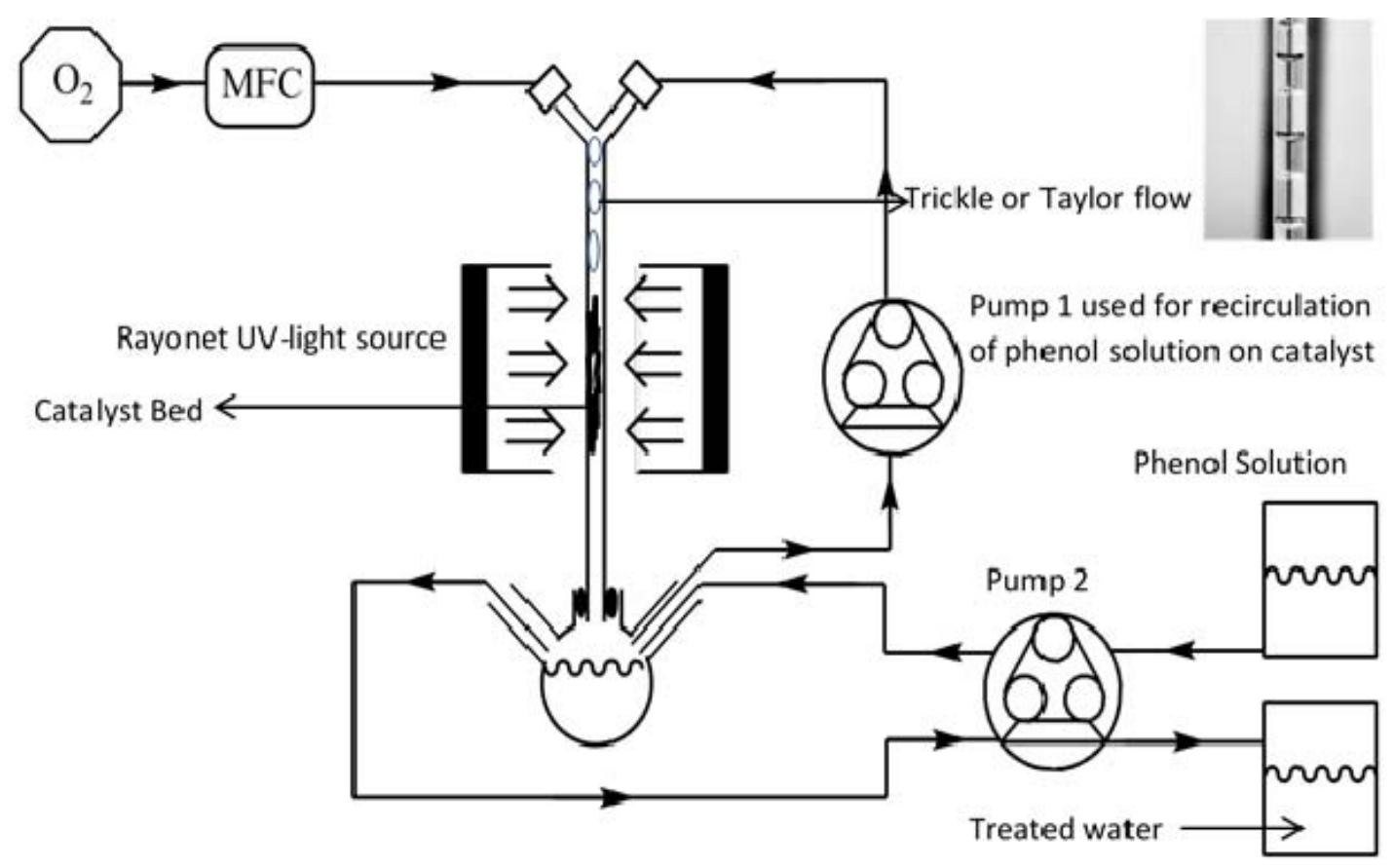

Figure 1. Schematic Diagram of the Taylor flow reactor system.

\section{Results And Discussion}

\subsection{Catalyst characterization}

The phase structure, crystallite size, and crystallinity of $\mathrm{TiO}_{2}$ play an important role in photocatalytic activity, with many studies confirming that the anatase phase of $\mathrm{TiO}_{2}$ shows higher photocatalytic activity than brookite or rutile phase [16]. The XRD patterns of Au$\mathrm{Pd} / \mathrm{TiO}_{2} \mathrm{P} 25$ catalysts calcined at $120{ }^{\circ} \mathrm{C}$ for 24 hours are shown in Figure S2 (supporting information). The SEM and TEM images of $\mathrm{Au}-\mathrm{Pd} / \mathrm{TiO}_{2} \mathrm{P} 25$ catalysts are shown in Figure S6. The figure shows typical surfaces of doped TiO2 (Degussa P25). The TEM images showed metal nanoparticles were highly dispersed with some regions of $\mathrm{TiO}_{2}$ doped with metals and some without doping. The EDS mapping (Figure S7) showed uniform metal dispersion over the surface of $\mathrm{TiO}_{2}$. 
The average crystal size of the $\mathrm{TiO}_{2}$ was found to be a mixture of anatase crystallites $(22.3$ $\mathrm{nm})$ and rutile crystallites $(34.1 \mathrm{~nm})$ as shown in Table 1. There were no peaks that indicate the presence of the metal nanoparticles or their metal oxides, which indicates high metal dispersion with the size of the metals nanoparticles below the detection limit of $\sim 4 \mathrm{~nm}[14]$. In case of the bimetallic $\mathrm{Au}-\mathrm{Pd} / \mathrm{TiO}_{2}$ catalysts, the nanoparticles are more likely to be individual metals than the metal alloys.

\section{Table 1.}

The physico-chemical properties of $\mathrm{Au}-\mathrm{Pd}$ nanoparticles supported on $\mathrm{TiO}_{2}$

\begin{tabular}{|c|c|c|c|c|c|}
\hline \multirow[t]{2}{*}{ Catalyst } & \multirow{2}{*}{$\begin{array}{c}\text { BET surface } \\
\text { area } \\
\left(\mathrm{m}^{2} \mathrm{~g}^{-1}\right)\end{array}$} & \multirow{2}{*}{$\begin{array}{l}\text { Pore volume } \\
\qquad\left(\mathrm{cm}^{3} \mathrm{~g}^{-1}\right)\end{array}$} & \multicolumn{2}{|c|}{ Crystallite size* } & \multirow{2}{*}{$\begin{array}{c}\text { Band Gap** } \\
(\mathrm{eV})\end{array}$} \\
\hline & & & Anatase & Rutile & \\
\hline $1 \% \mathrm{Au} / \mathrm{TiO}_{2}$ & 43.6 & 0.10 & 22.3 & 31.6 & 3.01 \\
\hline $0.75 \% \mathrm{Au}-0.25 \% \mathrm{Pd} / \mathrm{TiO}_{2}$ & 44.8 & 0.12 & 22.2 & 34.2 & 2.97 \\
\hline $0.5 \% \mathrm{Au}-0.5 \% \mathrm{Pd} / \mathrm{TiO}_{2}$ & 45.8 & 0.14 & 22.4 & 35.3 & 2.99 \\
\hline $0.25 \mathrm{Au} \%-0.75 \mathrm{Pd} / \mathrm{TiO}_{2}$ & 48.8 & 0.15 & 21.9 & 34.7 & 2.97 \\
\hline $0.5 \% \mathrm{Pd} / \mathrm{TiO}_{2}$ & 47.1 & 0.13 & 22.9 & 34.6 & 2.97 \\
\hline $1 \% \mathrm{Pd} / \mathrm{TiO}_{2}$ & 49.8 & 0.10 & 22.2 & 32.8 & 2.98 \\
\hline $\mathrm{TiO}_{2} \mathrm{P} 25$ Degussa & 55.0 & 0.19 & 15.6 & 19.9 & 3.12 \\
\hline
\end{tabular}

${ }^{*}$ Crystallite size was calculated using Scherrer equation, $\mathbf{D}=\mathbf{K} \boldsymbol{\lambda} / \boldsymbol{\beta C O S} \boldsymbol{\theta},{ }^{* *}$ Band gap energies were calculated using the formula, $\boldsymbol{E}=\left(\boldsymbol{h}^{*} \boldsymbol{c}\right) / \lambda$, where; $h=$ Planck constant $\left(6.63 \times 10^{-34} \mathrm{~J} \mathrm{~s}^{-1}\right)$, $\lambda=$ cut off wavelength from the $\%$ reflectance graph, $c=$ speed of light in vacuum $\left(\approx 3 \times 10^{8} \mathrm{~m} \mathrm{~s}^{-1}\right)$, and $1 \mathrm{eV}=1.6 \times 10^{-19} \mathrm{~J}$. 
The surface area and pore volumes of the catalysts obtained by BET $\mathrm{N}_{2}$ isotherm are shown in Table 1. As expected, the results show a decrease in the surface area of the catalyst after metal deposition. From the Diffuse Reflectance UV-Vis spectra (Figure 2) an absorption peak, with a maximum at $580 \mathrm{~nm}$ was observed for the $1 \mathrm{wt} \% \mathrm{Au} / \mathrm{TiO}_{2}$. This is attributed to the surface Plasmon resonance of spatially confined electrons in the $1.0 \mathrm{wt} \% \mathrm{Au} / \mathrm{TiO}_{2}$ catalyst. There are also band gap excitations in the region near $400 \mathrm{~nm}$ in all the spectra taken. The absorbance of the $\mathrm{Au}-\mathrm{Pd} / \mathrm{TiO}_{2}$ catalysts varied with the content of $\mathrm{Au}$ in $\mathrm{TiO}_{2}$; which could be attributed to the charge-transfer transition between the d electrons of the dopant and the Conduction Band (CB) or Valance Band (VB) of $\mathrm{TiO}_{2}$ [18-20]. Based on the position of their absorbance maximum (Figure S3, supporting information), the band gap values of $\mathrm{TiO}_{2} \mathrm{P} 25, \mathrm{Au}, \mathrm{Pd}$ and $\mathrm{Au}-\mathrm{Pd} / \mathrm{TiO}_{2}$ P25 were calculated and are shown in the Table 1. It was observed that the $\mathrm{Au}-\mathrm{Pd} / \mathrm{TiO} 2$ catalysts showed stronger visible light absorption than pristine $\mathrm{TiO}_{2} \mathrm{P} 25$, suggesting a greater potential for photocatalytic activity in the visible light to enhance the photodegradation of phenolics under natural sunlight. 


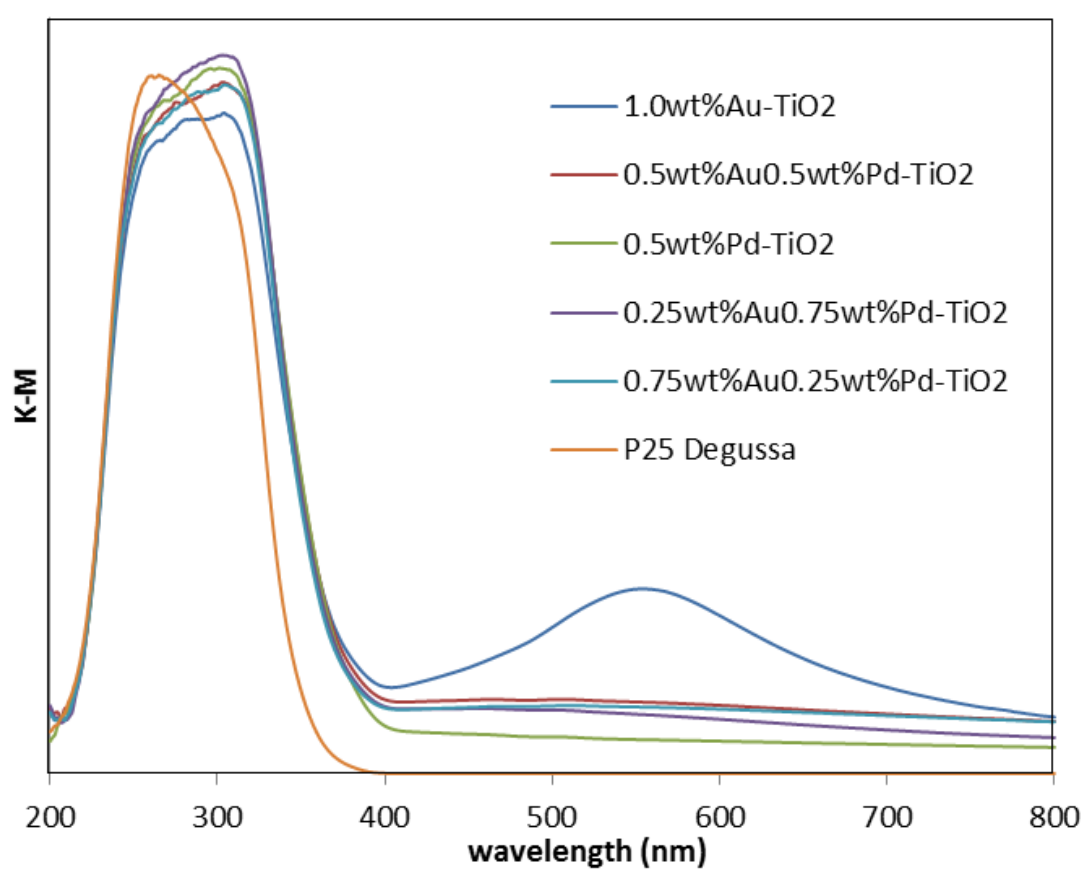

Figure 2. The DR UV-Vis spectra of Au-Pd nanoparticles supported on $\mathrm{TiO}_{2} \mathrm{P} 25$.

\subsection{Photocatalytic degradation of phenol using batch reactor}

The plot of total concentration of phenol as a function of time using UV irradiation is given in Figure 3. From the comparison of $\mathrm{Au}-\mathrm{Pd}$ and $\mathrm{Pd}$ supported catalysts with $\mathrm{TiO}_{2} \mathrm{P} 25,1 \% \mathrm{Pd} / \mathrm{TiO}_{2}$ showed the highest phenol degradation rate with $86.4 \%$ conversion of Phenol to $\mathrm{CO}_{2}$ and $\mathrm{H}_{2} \mathrm{O}$ after 120 min with $\mathrm{O}_{2}$ whereas the $0.5 \% \mathrm{Pd} / \mathrm{TiO}_{2}$ gives $79.7 \%$ and $1 \% \mathrm{Au} / \mathrm{TiO}_{2}$ gives $73.4 \%$ conversion. For $0.5 \% \mathrm{Au} 0.5 \% \mathrm{Pd} / \mathrm{TiO}_{2}, 0.25 \% \mathrm{Pd} 0.75 \% \mathrm{Au} / \mathrm{TiO}_{2}$ and $0.25 \% \mathrm{Au} 0.75 \mathrm{Pd} \% / \mathrm{TiO}_{2}$ the $\%$ conversion of phenol is $69.0 \%, 64.4 \%$ and $41.8 \%$ respectively which are all lower than the monometallic catalysts. In contrast, $64.5 \%$ degradation is obtained with unmodified $\mathrm{TiO}_{2} \mathrm{P} 25$. 


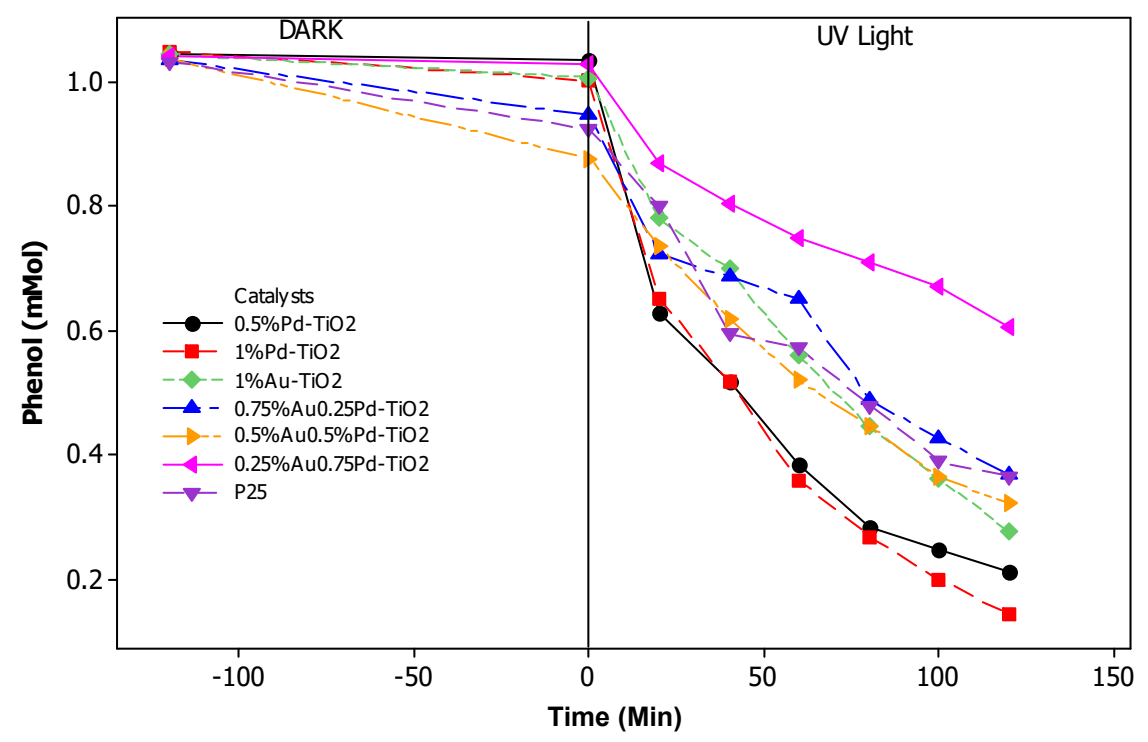

Figure 3. Photocatalytic degradation of phenol in $\mathrm{UV}$ using $\mathrm{O}_{2}$ in the slurry type batch reactor.

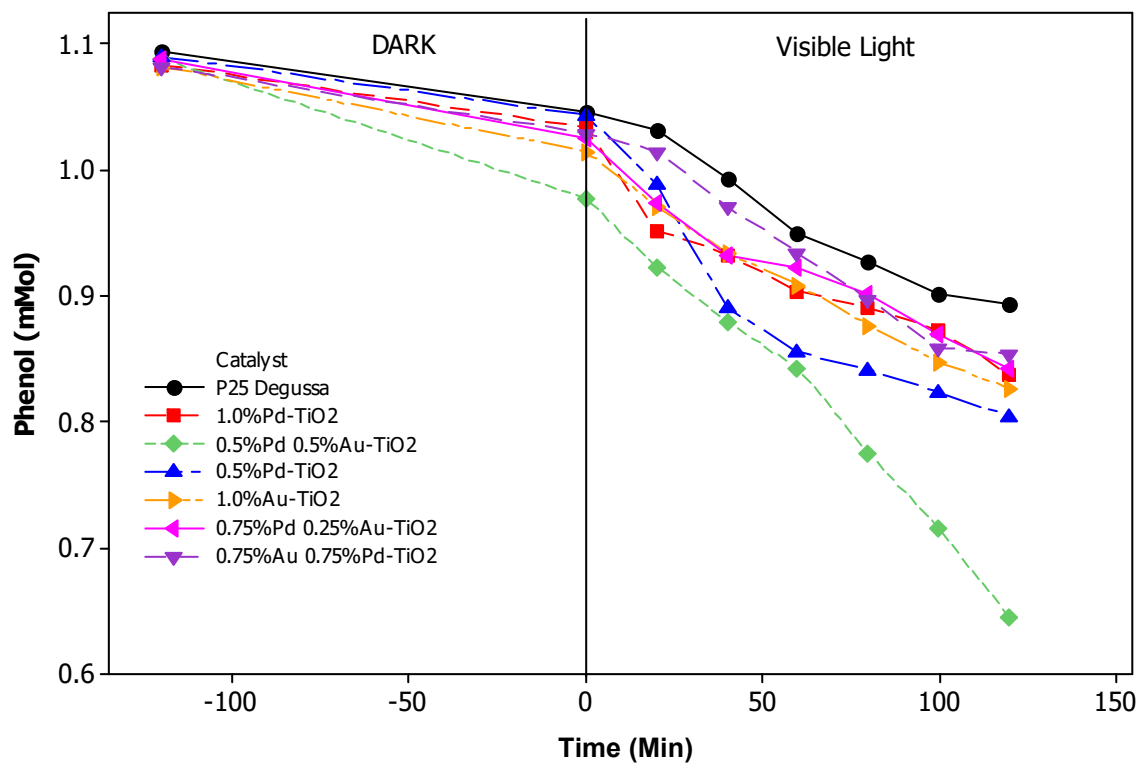

Figure 4. Photocatalytic degradation of phenol in the visible light $(555 \mathrm{~nm})$ using $\mathrm{O}_{2}$ in the slurry type batch reactor.

From the dark results, although $2-10 \%$ of phenol adsorption was observed, but there was no direct correlation between adsorbed phenol concentration with phenol degradation rate, it could 
be rather complicated due to several simultaneous effects including excitation of Au electrons to the conduction band of $\mathrm{TiO}_{2}$ under UV irradiation causing detrimental effect on space-charge separation of electron-hole pairs [21-22].

Utilizing $\mathrm{UV}, 1 \% \mathrm{Pd} / \mathrm{TiO}_{2}$ showed faster reaction rate for phenol degradation than $\mathrm{Au}-\mathrm{Pd} / \mathrm{TiO}_{2}$ catalyst, while $1 \% \mathrm{Au} / \mathrm{TiO}_{2}$ and $0.5 \% \mathrm{Au}-0.5 \% \mathrm{Pd} / \mathrm{TiO}_{2}$ showed faster phenol degradation rates under visible light (Figure 4). The synergetic effect of $\mathrm{Au}-\mathrm{Pd} / \mathrm{TiO}_{2}$ showed highly enhanced activity for phenol degradation in the visible light region which is similar to other reports attributed to localized surface plasmonic effect and localized heating effect upon irradiation with visible light [23].

The Photocatalytic degradation of phenolics is often determined by using pseudo-first order kinetics [24-26]. The initial rate of Phenol Photocatalytic degradation was determined after the first 20min of the reaction by assuming Pseudo-first order kinetics with respect to the concentration of the bulk solution of phenol.

$$
r=\frac{d C}{d t}=k_{\text {obs }} C
$$

Integrating the equation with the following restriction $\mathrm{C}=\mathrm{C}_{0}$ at $\mathrm{t}=0$, with $\mathrm{C}_{0}$ being the initial concentration of the phenol solution and the reaction time yields the following expression:

$$
\ln \left(\frac{C_{0}}{C}\right)=-k_{o b s} t
$$

The expression $k_{o b s}$ is the apparent pseudo-first-order rate constant and is affected by the concentration of phenol. The plot of $-\ln \left(\mathrm{C}_{0} / \mathrm{C}\right)$ versus time for phenol degradation using the slurry batch reactor in $\mathrm{O}_{2}$ with the different modified photo catalyst in UV light is shown in Figure 5 and the phenol degradation rates obtained with each catalyst are shown in Table 2. 


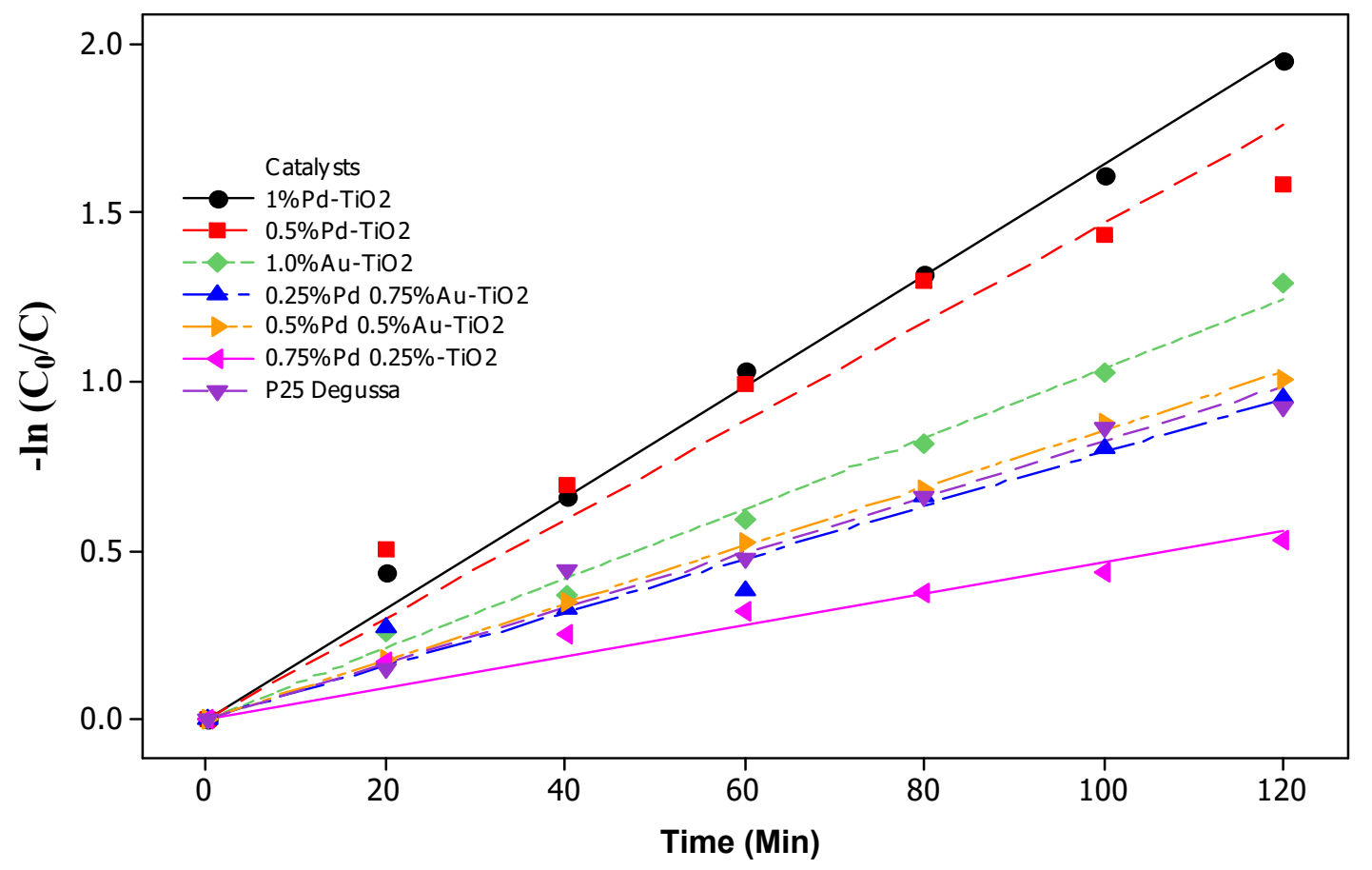

Figure 5. Pseudo-first order kinetics of photocatalytic degradation of phenol in $\mathrm{O}_{2}$ using the slurry type batch reactor.

\section{Table 2.}

Pseudo-first order kinetic constants for the photocatalytic degradation of Phenol

\begin{tabular}{ll}
\hline Catalyst & $\begin{array}{l}\text { Rate Constant } \\
\text { kphenol }\left(\mathrm{min}^{-1}\right)\end{array}$ \\
\hline $\mathrm{TiO}_{2} \mathrm{P} 25$ & 0.0047 \\
$1 \mathrm{wt} \% \mathrm{Au} / \mathrm{TiO}_{2}$ & 0.0055 \\
$0.75 \mathrm{wt} \% \mathrm{Au}-0.25 \mathrm{wt} \% \mathrm{Pd} / \mathrm{TiO}_{2}$ & 0.0039 \\
$0.5 \mathrm{wt} \% \mathrm{Au}-0.5 \mathrm{wt} \% \mathrm{Pd} / \mathrm{TiO}_{2}$ & 0.0046 \\
$0.25 \mathrm{wt} \mathrm{Au}-0.75 \mathrm{wt} \% \mathrm{Pd} / \mathrm{TiO}_{2}$ & 0.0025 \\
$0.5 \mathrm{wt} \% \mathrm{Pd} / \mathrm{TiO}_{2}$ & 0.0056 \\
$1 \mathrm{wt} \% \mathrm{Pd} / \mathrm{TiO} 2$ & 0.0058 \\
\hline
\end{tabular}




\subsection{The effect of catalyst loading on photocatalysis}

To determine the optimal catalyst loading, a set of experiments with varying catalyst mass in the range $0.1-0.4 \mathrm{~g}$ using $0.5 \mathrm{wt} \% \mathrm{Pd} / \mathrm{TiO}_{2}$ as catalyst was studied at $\mathrm{pH} 6.4$ over $80 \mathrm{~min}$ (Figure 6). An increase in the amount of catalyst provides an increased number of active sites for adsorption; however, this also causes a simultaneous increase in solution opacity which further causes a decrease in the penetration of UV light. This suggests that the amount of photo-catalyst to be used should maintain a balance between these two opposing effects [27-30]. For this study, clearly the photocatalytic degradation for phenol increases as the catalyst loading is increased from $0.1 \mathrm{~g}$ to $0.3 \mathrm{~g}$ but when the catalyst loading is increased further to $0.4 \mathrm{~g}$, the amount adsorbed in the first $20 \mathrm{~min}$ increased while the rate of degradation decreases after $40 \mathrm{~min}$. These show that the optimum catalyst loading to be used is $0.3 \mathrm{~g}$ in $100 \mathrm{ml}$ of the phenol solution.

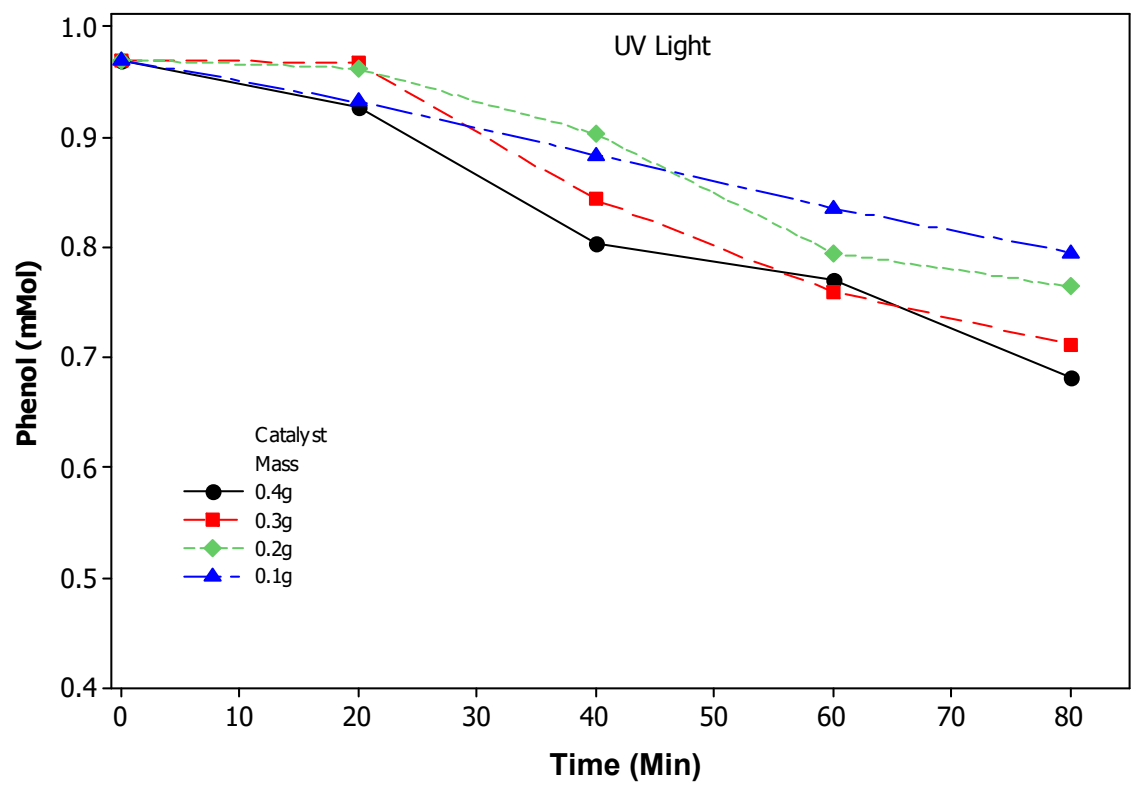

Figure 6. Effect of catalyst loading on the Photocatalytic degradation of Phenol with $0.5 \mathrm{wt} \% \mathrm{Pd} / \mathrm{TiO}_{2}$ in $\mathrm{O}_{2}$. 
HPLC analysis suggests that the polymerization of phenol and formation of intermediates like catechol, Pyrogallol and Benzoquinone occurred immediately after the first 20mins of irradiation with UV light. This was evident from the brownish colors formed which slowly disappeared. The results of HPLC analysis indicated that the polymer was transformed to hydroxylated products that were the same as those intermediates produced in photocatalysis of phenol, and further oxidized via organic acids to $\mathrm{CO}_{2}$ in the course of the photocatalytic degradation of Phenol [31].

\subsection{Stability and reusability of the catalyst}

To develop a continuous process, stability and reusability of any photocatalyst is critical to develop potential practical applications [32-33]. Post reaction, $\mathrm{TiO}_{2} \mathrm{P} 25,0.5 \mathrm{wt} \% \mathrm{Pd} / \mathrm{TiO}_{2}$ and $0.5 \% \mathrm{Pd}-0.5 \% \mathrm{Au} / \mathrm{TiO}_{2}$ catalysts were recovered by filtration, washed and dried and evaluated for reusability under the same experimental conditions (Figure 7). Significant loss in activity was

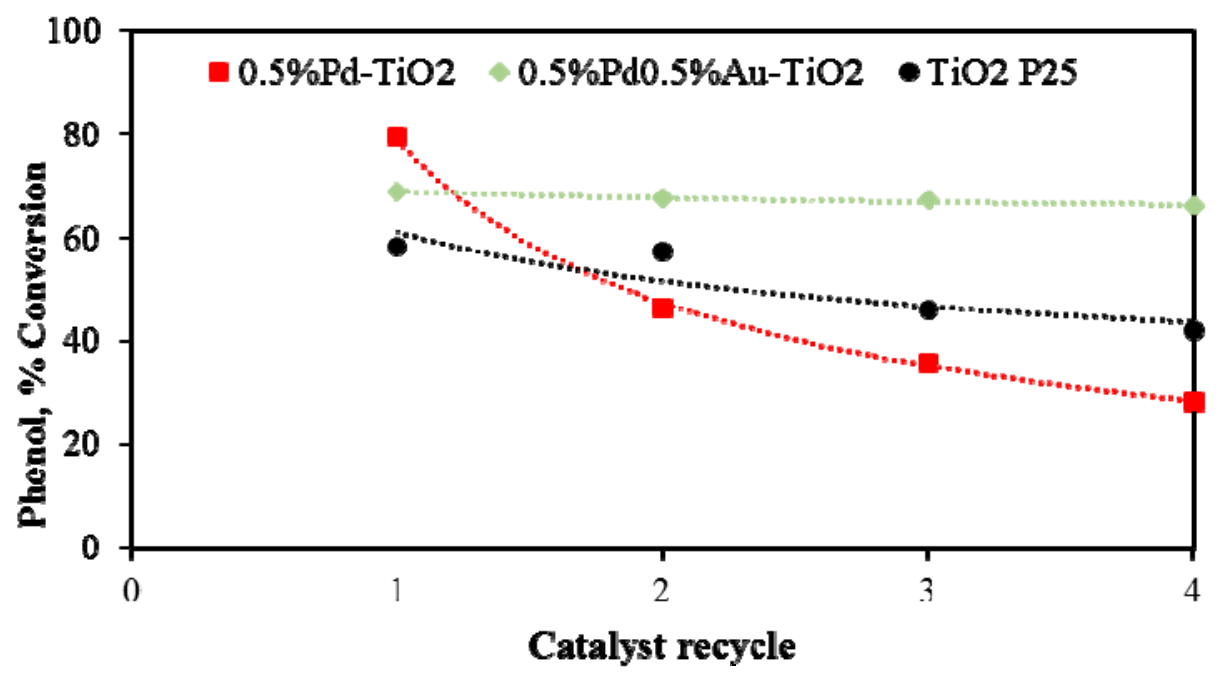

Figure 7. Catalyst reusability in the Photocatalytic degradation of Phenol. 


\section{Table 3.}

The metal content of fresh and used $\mathrm{Au}-\mathrm{Pd} / \mathrm{TiO}_{2}$ catalysts as determined by ICP-OES analysis

\begin{tabular}{lcccc}
\hline \multicolumn{1}{c}{ Catalyst } & \multicolumn{2}{c}{ Fresh } & \multicolumn{2}{c}{ Used catalyst } \\
\cline { 2 - 5 } & $\% \mathrm{Au}$ & $\% \mathrm{Pd}$ & $\% \mathrm{Au}$ & $\% \mathrm{Pd}$ \\
\hline $1 \mathrm{wt} \% \mathrm{Au} / \mathrm{TiO}_{2}$ & 1.02 & - & 0.96 & - \\
$0.75 \mathrm{wt} \% \mathrm{Au}-0.25 \mathrm{wt} \% \mathrm{Pd} / \mathrm{TiO}_{2}$ & 0.74 & 0.23 & 0.60 & 0.11 \\
$0.5 \mathrm{wt} \% \mathrm{Au}-0.5 \mathrm{wt} \% \mathrm{Pd} / \mathrm{TiO}_{2}$ & 0.46 & 0.40 & 0.46 & 0.39 \\
$0.25 \mathrm{wt} \mathrm{Au}-0.75 \mathrm{wt} \% \mathrm{Pd} / \mathrm{TiO}_{2}$ & 0.21 & 0.72 & 0.19 & 0.68 \\
$0.5 \mathrm{wt} \% \mathrm{Pd} / \mathrm{TiO}_{2}$ & - & 0.43 & - & 0.33 \\
\hline
\end{tabular}

observed for $\mathrm{TiO}_{2}$ and monometallic $\mathrm{Pd} / \mathrm{TiO}_{2}$ catalysts which could be due to metal leaching as well as deposition of polymeric species on the catalysts surface. Besides metal leaching, the loss of activity could also be due to poisoning of the catalyst surface with intermediates. The $\mathrm{Pd}$ metal content of the fresh and used $\mathrm{Pd} / \mathrm{TiO}_{2}$ catalyst using ICP-OES analysis (Table 3) showed a clear decrease in Pd content on used catalyst due to metal leaching. However, Pd metal content for fresh and used $0.5 \% \mathrm{Au}-0.5 \% \mathrm{Pd} / \mathrm{TiO}_{2}$ and $0.25 \% \mathrm{Au}-0.75 \% \mathrm{Pd} / \mathrm{TiO}_{2}$ was pretty consistent within the experimental errors, which indicated that bimetallic Au-Pd catalysts were more stable to leaching in the photocatalytic conversion of Phenol to water. This was further supported by the reusability of recovered bimetallic Au-Pd catalysts.

\subsection{Comparison of photo and thermal degradation of phenol in UV, Visible and dark regions}

Comparing the amount of phenol converted using the visible light and the UV light (Figure 8), it was shown that the bimetallic $0.5 \% \mathrm{Pd}-0.5 \% \mathrm{Au} / \mathrm{TiO}_{2} \mathrm{P} 25$ catalyst was not only more stable to leaching but also had significantly enhanced Photocatalytic activity in visible light region. This could be attributed to their ability to suppress the recombination of the photogenerated electron- 
hole pairs in the reaction. Interaction between $\mathrm{Au}-\mathrm{Pd}$ helps to anchor $\mathrm{Pd}$ on $\mathrm{TiO}_{2}$ more strongly thus suppressing the leaching of $\mathrm{Pd}$. Also the $0.5 \% \mathrm{Au}-0.5 \% \mathrm{Pd} / \mathrm{TiO}_{2}$ catalyst showed remarkable ability to both adsorb and degrade phenol thermally in the dark region conversion, which can allow for continuous day and night operation in real life solar photodegradation of phenolics (Figure 4). The thermal catalytic efficiency of $\mathrm{TiO}_{2} \mathrm{P} 25$ was further compared with $0.5 \% \mathrm{Pd}$ $0.5 \% \mathrm{Au} / \mathrm{TiO}_{2}$ in terms of the rate of the reaction. Here the rate at which $0.5 \% \mathrm{Pd}-0.5 \% \mathrm{Au} / \mathrm{TiO} 2$ thermally degraded phenol in the absence of light is 2.0 times higher than the P25 under the same conditions.

$0.5 \% \mathrm{Pd}-0.5 \% \mathrm{Au} / \mathrm{TiO}_{2}$ catalyst showed very stable catalytic activity over 4 recycles which was complimentary to metal content analysis of used catalyst, hence bimetallic $\mathrm{Pd}-\mathrm{Au} / \mathrm{TiO}_{2} \mathrm{P} 25$ could be the potential catalyst for continuous flow operation.

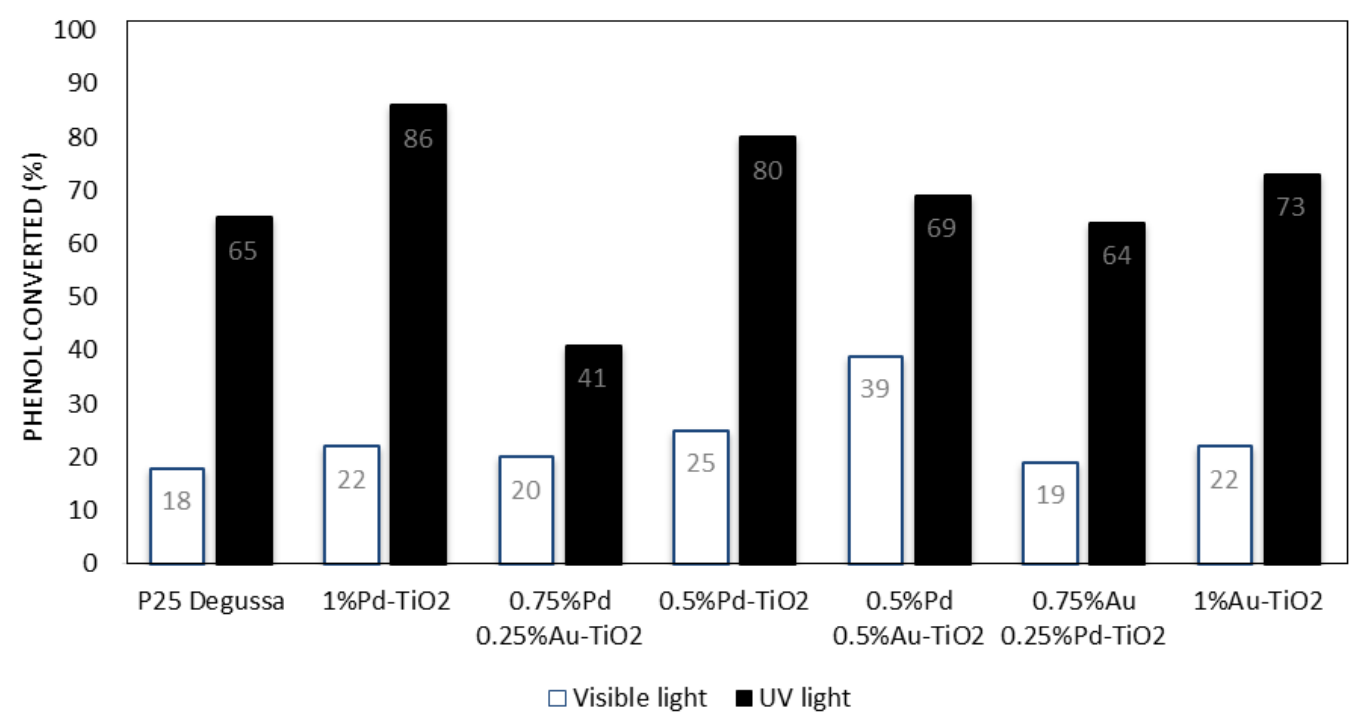

Figure 8. Comparison of Phenol, \% Conversion using the Visible and UV light in $\mathrm{O}_{2}$ in the slurry Batch reactor.

\subsection{Photocatalytic degradation of phenol using continuous trickle-bed reactor}


Photocatalytic degradation of phenol in continuous flow operation was studied using trickle bed reactor (Figure 9). Increase in the contact time between phenol and the catalyst in the presence of sufficient $\mathrm{O}_{2}$ promoted the photodegradation of phenol to higher conversions. It was observed that the conversion of phenol to $\mathrm{CO}_{2}$ and water is limited by the availability of oxidant in the reaction. Mass transfer limitations often occur in immobilized photocatalytic systems [3435]. Photocatalytic degradation of phenol showed that the removal efficiency of the catalyst was 99.9\% when $\mathrm{TiO}_{2} \mathrm{P} 25$ was used in the Trickle Bed reactor in the presence of hydrogen peroxide as the oxidant. While $71.9 \%$ conversion was achieved when $\mathrm{TiO}_{2} \mathrm{P} 25$ was used with $\mathrm{O}_{2}$ and $70.3 \%$ when $0.5 \% \mathrm{Pd} / \mathrm{TiO}_{2}$ was used under the same reaction conditions. These results indicated that rate of phenol degradation using $\mathrm{Au}-\mathrm{Pd} / \mathrm{TiO}_{2}$ photocatalyst could be affected by the deposition of intermediates on the surface of the catalyst.

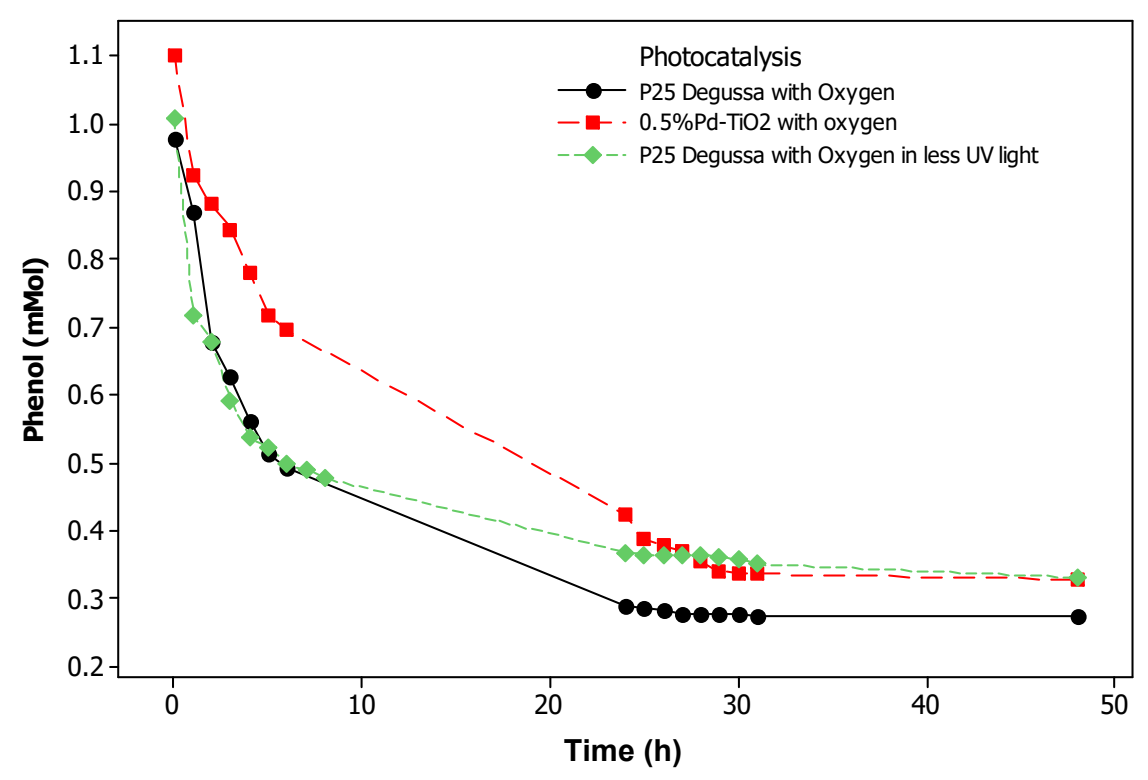

Figure 9. Photocatalytic degradation of phenol in $\mathrm{O}_{2}$ using the Trickle Bed reactor.

To evaluate catalyst stability in continuous process, further tests were conducted using the fresh catalyst in the Trickle Bed reactor with $\mathrm{O}_{2}$. In a control experiment with limiting the 
intensity of UV-light, the formation of polymeric species on the surface of the catalyst during the reaction was noticed. In a separate experiment conducted by limiting $\mathrm{O}_{2}$ and increased intensity of UV light, the deposition of species on the surface of the catalyst was again observed. As shown in Figure S4 (supporting information), it is evident that the availability of $\mathrm{O}_{2}$ is vital for the complete decomposition of intermediates species formed in the reaction. If the $\mathrm{TiO}_{2} \mathrm{P} 25$ catalyst has both sufficient oxygen and UV irradiation complete conversion of Phenol to $\mathrm{CO}_{2}$ is evident through the catalyst retaining its original color. After the catalytic activity test, the used catalyst was analyzed using Temperature Program Oxidation (TPO). (Figure S5, supporting information). TPO of used catalyst from activity test performed by limiting $\mathrm{O}_{2}$ showed that carbonic species formed were more difficult to remove and required higher temperatures. In order to optimize and properly design the regeneration of deactivated catalysts, knowledge of the carbonaceous burning kinetics is desirable [36]. The result of this analysis is also presented in Table S1 (supporting information) depicting the wt $\%$ of carbonaceous species on the catalyst.

\subsection{Photocatalytic degradation of phenol using continuous Taylor flow reactor}

The photocatalytic efficiency of the monometallic $\mathrm{Pd}$ and $\mathrm{Au}$ on $\mathrm{TiO}_{2}$ catalyst can be enhanced by reducing the mass transfer resistance and increasing the availability of oxygen by using the Taylor flow reactor running gas liquid slugs, where $\mathrm{O}_{2}$ replenishes the catalyst surface continually. Hence, the catalyst surface was not deactivated with carbonaceous deposits thereby increasing the stability and life-time of the catalyst under continuous mode [37-38]. For the $0.5 \% \mathrm{Pd}-0.5 \% \mathrm{Au} / \mathrm{TiO}_{2}$ over $76 \%$ phenol is converted and this is retained for 52 hrs (Figure 10). It should be noted that these trends continued over the $52 \mathrm{hr}$ run. Furthermore the photo-response 
of the $0.5 \% \mathrm{Pd}-0.5 \% \mathrm{Au} / \mathrm{TiO}_{2}$ in the visible light region, as discussed earlier, makes this a viable catalyst for industrial application in wastewater treatment.

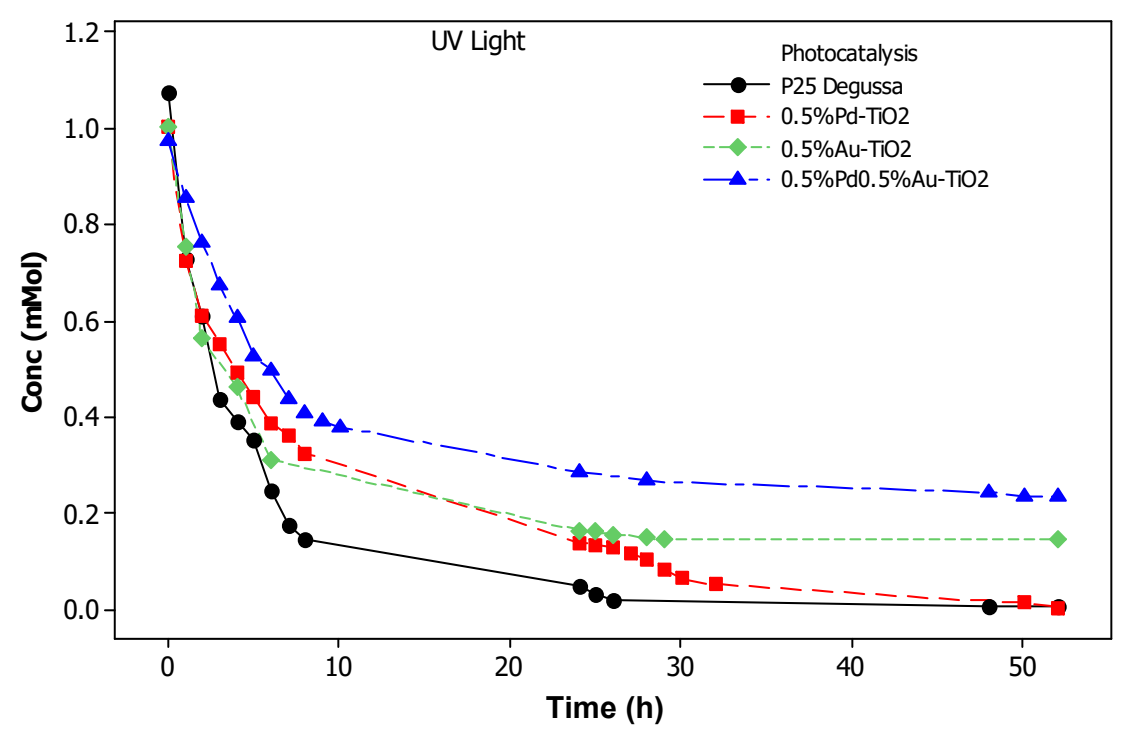

Figure 10. Photocatalytic degradation of phenol in $\mathrm{O}_{2}$ using the Taylor flow reactor.

\section{Conclusions}

In present study, it was demonstrated that $\mathrm{TiO}_{2} \mathrm{P} 25, \mathrm{Pd}, \mathrm{Au}$ and $\mathrm{Au}-\mathrm{Pd} / \mathrm{TiO}_{2}$ monometallic and bimetallic catalysts show high photocatalytic activity under UV and Visible light illumination. Monometallic Pd supported catalysts gradually deactivate due to leaching of Pd, however $\mathrm{Au}-\mathrm{Pd} / \mathrm{TiO}_{2} \mathrm{P} 25$ suppresses $\mathrm{Pd}$ leaching and enhances photocatalytic activity. Photodegradation of phenolics is mass transfer limited with respect to availability of oxygen on the catalyst surface. It was observed that the combination of poor mass transfer and excess UV within the trickle bed reactor led to the formation of heavier hydrocarbon species and some deactivation of the catalyst. However this process could be significantly reduced by saturating the catalyst with $\mathrm{O}_{2}$ and then providing a sufficient volume of solution in order to desorb any intermediates, effectively washing the catalyst. Such a process could be achieved using the alternating gas- 
liquid slugs flow pattern produced in the Taylor flow reactor and showed stable continuous activity over the 52 hour operating window.

\section{Acknowledgements}

The authors gratefully acknowledge financial Support from the STEP-B of National Research Institute for Chemical Technology (NARICT), Zaria as well as the recent Collaboration between the Center for the theory and Application of Catalysis (CenTACat) and NARICT.

\section{Supporting Information}

Additional information on batch reactor scheme, XRD diffraction patterns, comparison of various catalysts for phenol conversions over time, catalyst bed photos in the trickle bed reactor, weight of carbonaceous materials can be found in the supporting information.

\section{References}

[1] G. Panzera, V. Modafferi, S. Candamano, A. Donato, F. Frusteri, P.L. Antonucci, CO selective oxidation on ceria-supported Au catalysts for fuel cell application, J. of power sources, 135, 1 (2004) 177-183.

[2] W. Hou, N. A. Dehm, R.W.J. Scott, Alcohol oxidations in aqueous solutions using Au, Pd, and bimetallic AuPd nanoparticle catalysts, J. of Catal., 253, 1 (2008) 22-27.

[3] G. Li, J. Edwards, A.F. Carley, G.J. Hutchings, Direct synthesis of hydrogen peroxide from $\mathrm{H}_{2}$ and $\mathrm{O}_{2}$ using zeolite-supported Au-Pd catalysts, Catal. Tod., 122 (2007) 361-364. 
[4] C. Hamill, R. Burch, A. Goguet, D. Rooney, H. Driss, L. Petrov, M. Daous, Evaluation and mechanistic investigation of a AuPd alloy catalyst for the hydrocarbon selective catalytic reduction (HC-SCR) of NOx, Appl. Catal. B: Env., 147 (2014) 864-870.

[5] H.L. Abbott, A. Aumer, Y. Lei, C. Asokan, R.J. Meyer, M. Sterrer, S. Shaikhutdinov, H. Freund, CO Adsorption on Monometallic and Bimetallic Au-Pd Nanoparticles Supported on Oxide Thin Films, J. of P. Chem. C, 114, 40 (2010) 17099-17104.

[6] A. Mills; S.L. Hunte, An Overview of semiconductor photocatalysis, J. of Photochem. and Photobio. A: Chem., 108, 1 (1997) 1-35.

[7] M. Maicu, M.C. Hidalgo, G. Col'on, J.A. Nav'io, Comparative study of the photodeposition of $\mathrm{Pt}, \mathrm{Au}$ and $\mathrm{Pd}$ on pre-sulphated $\mathrm{TiO}_{2}$ for the photocatalytic decomposition of phenol, J. of Photochem. and Photobio. A: Chem., 217 (2011) 275-283.

[8] R. Su, R. Tiruvalam, Q. He, N. Dimitratos, L. Kesavan, C. Hammond, J.A. LopezSanchez, R. Bechstein, C.J. Kiely, G.J. Hutchings, F. Besenbacher, Promotion of Phenol Photodecomposition over $\mathrm{TiO}_{2}$ Using $\mathrm{Au}, \mathrm{Pd}$ and Au-Pd Nanoparticles, ACS Nano, 6, 7 (2012) 6284-6292.

[9] A. Mills, R. H Davis, D. Worsley, Purification by Semiconductor Photocatalysis, Chem. Soc. Rev., 22 (1993) 419-425.

[10] K. R. Reddy, M. Hassan, V. G. Gomes, Hybrid nanostructures based on titanium dioxide for enhanced photocatalysis, Appl. Catal. A. Gen., 489 (2015), 1-16. 
[11] K. R. Reddy, K. Nakata, T. Ochiai, T. Murakami, D. A. Tryk, A. Fujishima, Facile Fabrication and Photocatalytic Application of Ag Nanoparticles-TiO2 Nanofiber Composites, J. Nanosci. and Nanotech., 11, 4, (2011) 3692-3695.

[12] H. G. Manyar, P. Iliade, L. Bertinetti, S. Coluccia, G. Berlier, Structural and spectroscopic investigation of $\mathrm{ZnS}$ nanoparticles grown in quaternary reverse micelles, J. of Coll. and Inter. Sci., 354 (2011) 511-516.

[13] N.J. Peill, M.R. Hoffmann, Development and optimization of a $\mathrm{TiO}_{2}$-coated fiber--optic cable reactor: photocatalytic degradation of 4-chlorophenol, Env. Sci. \& Tech., 29, 12 (1995) 2974-2981.

[14] C. Mccullagh, N. Skillen, M. Adams, P.K.J. Robertson, Photocatalytic reactors for environmental remediation: a review, J. of Chem. Tech. and Biotech., 86, 8 (2011) 1002-1017.

[15] K. Mehrotra, G.S. Yablonsky, A.K. Ray, Kinetic studies of photocatalytic degradation in a $\mathrm{TiO}_{2}$ slurry system: Distinguishing working regimes and determining rate dependences, Ind. \& Eng. Chem. Res., 42, 11 (2003) 2273-2281.

[16] O. Carp, C.L. Huisman, A. Reller, Photoinduced reactivity of titanium dioxide, Prog. in Sol. St. Chem., 32, 1 (2004) 33-177.

[17] S. E. Wanke, P.C. Flynn, The sintering of supported metal catalysts, Catal. Rev., 12, 1 (1975) 93-135.

[18] L. Yang, G.H. Li, L.D. Zhang, Effects of surface resonance state on the Plasmon resonance absorption of Ag nanoparticles embedded in partially oxidized amorphous Si matrix., Appl. Phy. Lett., 76 (2000) 1537-1539. 
[19] X. Chen, S.S. Mao, Titanium dioxide nanomaterials: synthesis, properties, modifications, and applications, Chem. Rev., 107, 7 (2007) 2891-2959.

[20] L. Kumaresan, B. Palanisamy, M. Palanichamy, V. Murugesan, The Syntheses, Characterizations, and Photocatalytic Activities of Silver, Platinum, and Gold Doped $\mathrm{TiO}_{2}$ Nanoparticles, Env. Eng. Res., 16, 2 (2011) 81-90.

[21] M. Y. Seon, S. B. Rawal, J. E. Lee, J. Kim, H.-Y. Ryu, D.-W. Park, W. I. Lee, Sizedependence of plasmonic $\mathrm{Au}$ nanoparticles in photocatalytic behavior of $\mathrm{Au} / \mathrm{TiO}_{2}$ and Au@ $\mathrm{SiO}_{2} / \mathrm{TiO}_{2}$, Appl. Catal. A: Gen., 499 (2015) 47-54.

[22] T. Tsukasa, I. Shigeyoshi, K. Susumu, Y. Hiroshi, Effects of adsorbents used as supports for titanium dioxide loading on photocatalytic degradation of propyzamide, Env. Sci. \& Tech., 30, 4 (1996) 1275-1281.

[23] K. Masao, O. Ichiro, Eds., Photocatalysis: science and technology [M], Springer, Tokyo, (2003) 29-33.

[24] P. Xu, G. Zeng, D. Huang, L. Liu, C. Lai, M. Chen, C. Zhang, X. He, M. Lai, Y. He, Photocatalytic degradation of phenol by the heterogeneous $\mathrm{Fe}_{3} \mathrm{O}_{4}$ nanoparticles and oxalate complex system, RSC Advances, 4 (2014) 40828-40836.

[25] A. Hamza, J.T. Fatuase, S.M. Waziri, O.A. Ajayi, Solar Photocatalytic degradation of phenol using nanosized $\mathrm{ZnO}$ and $\alpha-\mathrm{Fe}_{2} \mathrm{O}_{3}$, J. of Chem. Eng. and Mat. Sci., 4, 7 (2013) 87-92.

[26] R. Qiu, L. Song, Y. Mo, D. Zhang, E. Brewer, Visible light induced photocatalytic degradation of phenol by polymer- modified semiconductors: Study of the influencing factors and the kinetics, Reac. Kinet. and Catal. Lett., 94, 1 (2008) 183-189. 
[27] K. Selvam, M. Muruganandam, I. Muthuvel, M. Swaminathan, The influence of inorganic oxidants and metal ions on semiconductor sensitized photodegradation of 4flurophenol, Chem. Eng. J., 128 (2007) 51-57.

[28] R. Vinu, M. Girighar, Kinetics of Simultaneous Photocatalytic Degradation of Phenolic Compounds and Reduction of Metal Ions with Nano-TiO2, Env. Sci. and Tech., 42 (2008) 913919.

[29] A.A. Adesina, Industrial exploitation of photocatalysis: progress, perspectives and prospects, Catalysis surveys from Asia, 8, 4 (2004) 265-273.

[30] K.M. Parida, S. Parija, Photocatalytic degradation of phenol under solar radiation using microwave irradiated zinc oxide, Solar Energy, 80, 8 (2006) 1048-1054.

[31] H. Chun, W. Yizhong, T. Hongxiao, Destruction of phenol aqueous solution by photocatalysis or direct photolysis, Chemosphere, 41, 8 (2000) 1205-1209.

[32] W. Li, Y. Bai, C. Liu, Z. Yang, X. Feng, X. Lu, N. K. van Der Laak, K.-Y. Chan, Highly Thermal Stable and Highly Crystalline Anatase $\mathrm{TiO}_{2}$ for Photocatalysis, Env. Sci. and Tech., 43 (2009) 5423-5428.

[33] Z.-Y. Ding, S. N.V.K. Aki, M. A. Abraham, Catatytic Supercritical Water Oxidation: Phenol Conversion Oxidation: Phenol Conversion, Env. Sci. and Tech., 29 (1995) 2748-2753.

[34] D.F. Ollis, E. Pelizzetti, N. Serpone, Photocatalyzed Destruction of water contaminants, Env. Sci. Tech., 25, 9 (1991) 1522-1529.

[35] A.K. Ray, A. ACM Beenackers, Novel swirl flow reactor for kinetic studies of semiconductor photocatalysis, AIChE J., 43, 10 (1997) 2571-2578. 
[36] B. Sanchez, M.S. Gross, B.D. Costa, C.A. Querini, Coke analysis by temperatureprogrammed oxidation: Morphology characterization, Appl. Catal. A: Gen., 364 (2009) 35-41.

[37] B. P. Chaplin, M. Reinhard, W. F. Schneider, C. Schuth, J. R. Shapley, T. J. Strathmann, C. J. Werth, Critical Review of Pd-Based Catalytic Treatment of Priority Contaminants in Water, Env. Sci. and Tech., 46 (2012) 3655-3670.

[38] S.-K., Lee; A. Mills, Platinium and Palladium in semiconductor Photocatalytic systems, Platinum Metals Review, 47, 2 (2003) 61-72. 


\section{$\underline{\text { Supporting Information }}$}

\section{Batch to Continuous Photocatalytic Degradation of Phenol using $\mathrm{TiO}_{2}$ and Au-Pd nanoparticles supported on $\mathrm{TiO}_{2}$}

Moses T. Yilleng, ${ }^{\dagger \S}$ Emmanuel C. Gimba, ${ }^{\dagger}$ George I. Ndukwe,${ }^{\dagger}$ Idris M. Bugaje, ${ }^{\S}$ David W. Rooney* and Haresh G. Manyar*

* Theoretical and Applied Catalysis Research Cluster, School of Chemistry and Chemical Engineering, Queen's University Belfast, David-Keir Building, Stranmillis Road, Belfast, BT9 $5 \mathrm{AG}, \mathrm{UK}$

†Department of Chemistry, Ahmadu Bello University, Zaria Nigeria

${ }^{\S}$ National Research Institute for chemical Technology, Zaria Nigeria

*Corresponding Author

Haresh G. Manyar

Email: h.manyar@qub.ac.uk

Phone: +442890976608

Fax: + 442890974687 


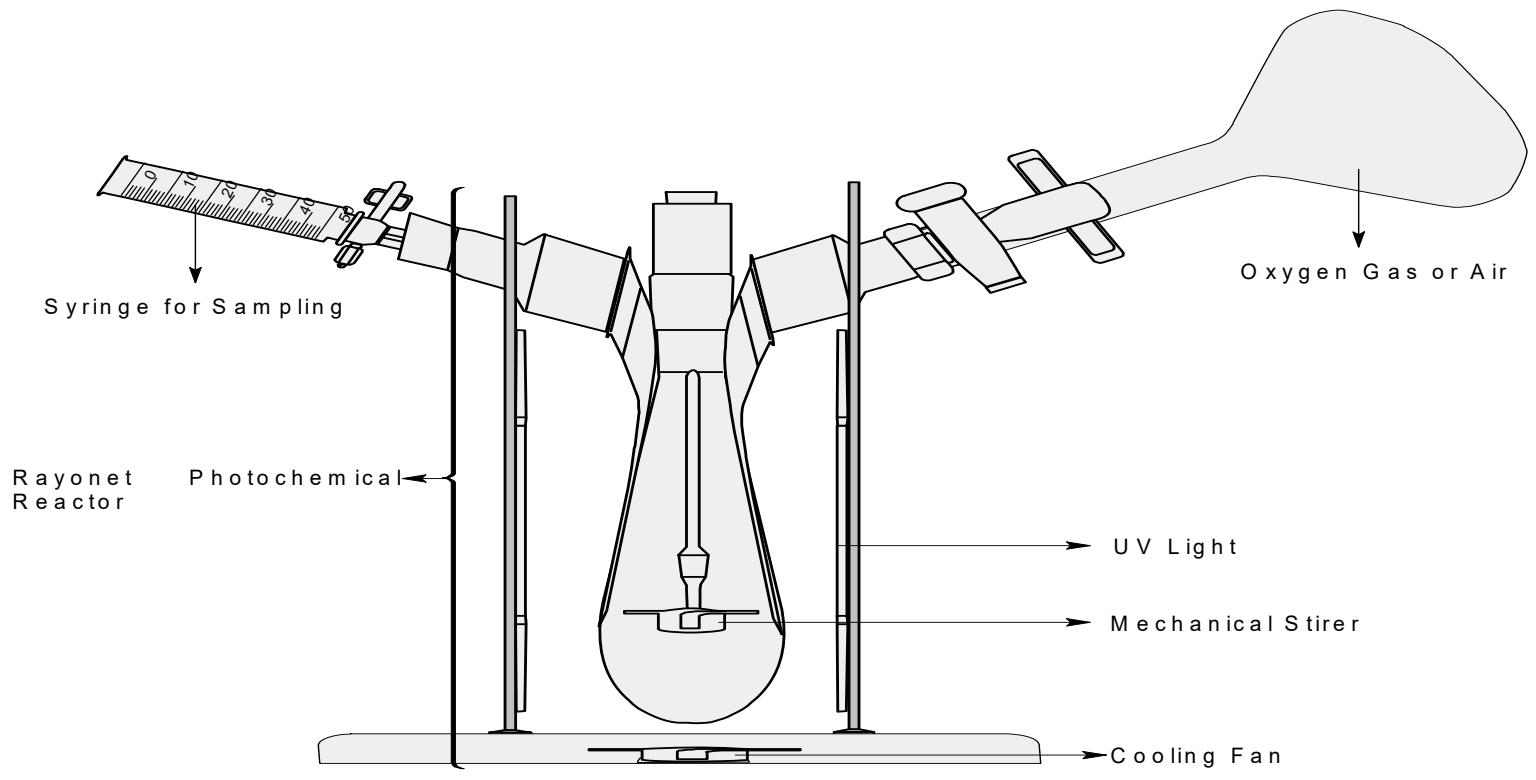

Figure S1. Diagram of the Slurry/Suspension Batch Setup using a Rayonet RMR-600 reactor.

The RMR-600 consists of a $279.4 \mathrm{~mm}$ long square base and $266.7 \mathrm{~mm}$ high (external measurements) chamber manufactured from Alzak aluminum. The reactor has 6 (8 Watt) UV lamps (350nm wavelength), with an arc length of $76.2 \mathrm{~mm}$ each (48 lamp Watts total). The distance between the UV lamp and the surface of the solute was set at $63.5 \mathrm{~mm}$. 


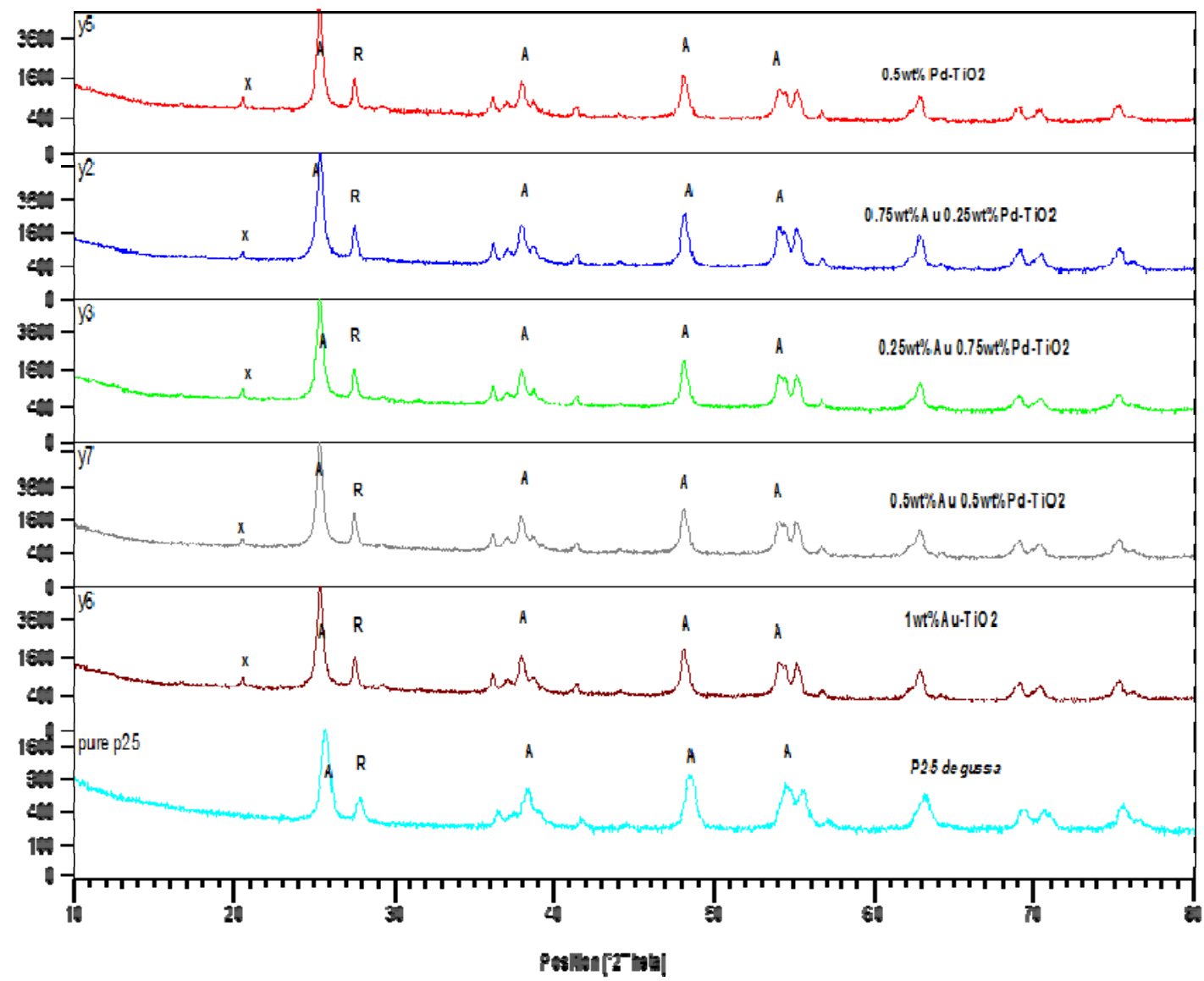

Figure S2. XRD Patterns of $\mathrm{Au}-\mathrm{Pd} / \mathrm{TiO}_{2}$ Prepared by sol Immobilization, diffraction peaks corresponding to the (i) A-anatase phase and (ii) R-rutile phase. 


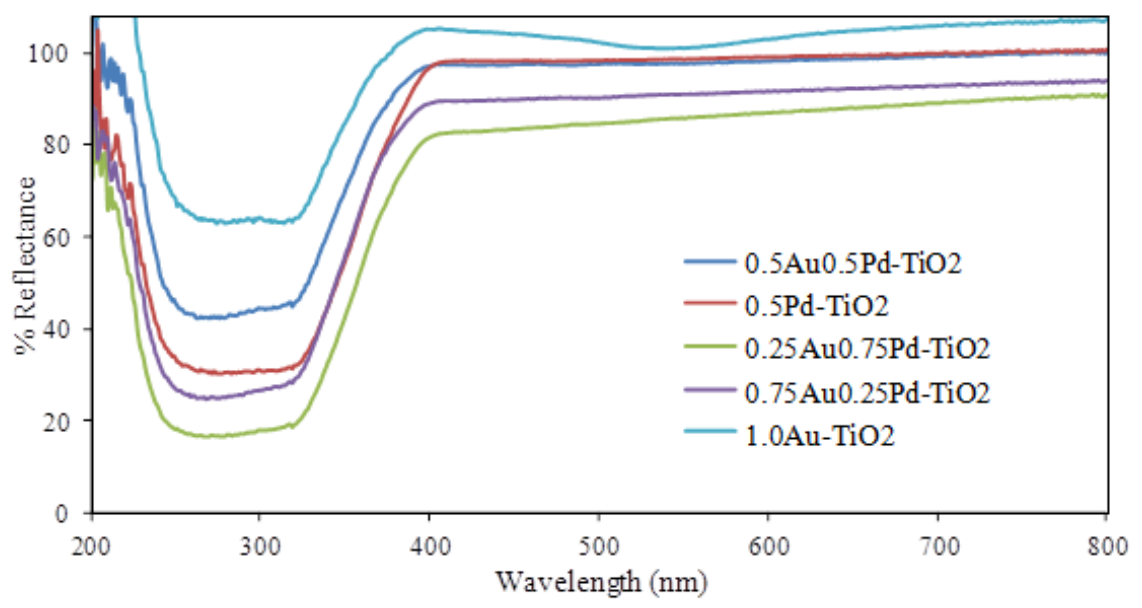

Figure S3. Diffuse Reflectance UV-Vis spectra of $\mathrm{Au}-\mathrm{Pd} / \mathrm{TiO}_{2}$.
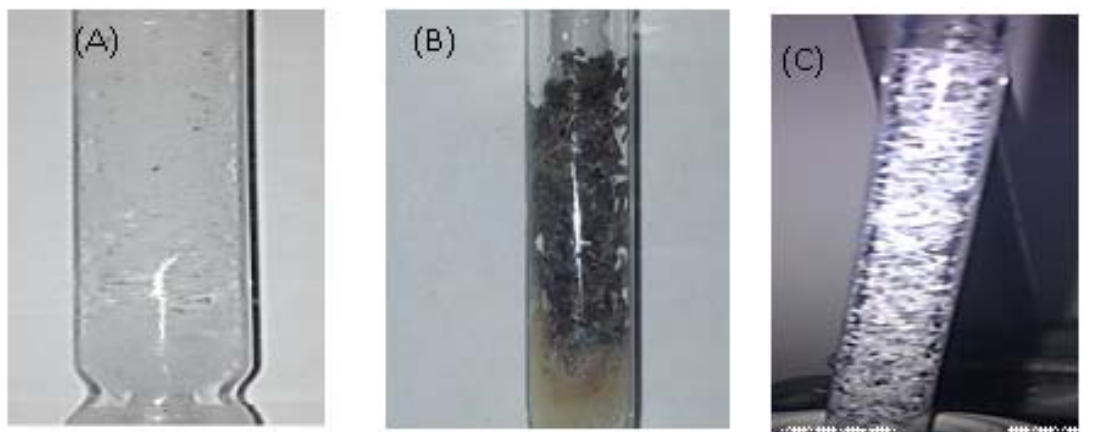

Figure S4. Picture of Catalyst Bed: (A) Fresh P25. (B) P25 with limited UV light in Trickle Bed (C) P25 in Oxygen with Taylor flow. 


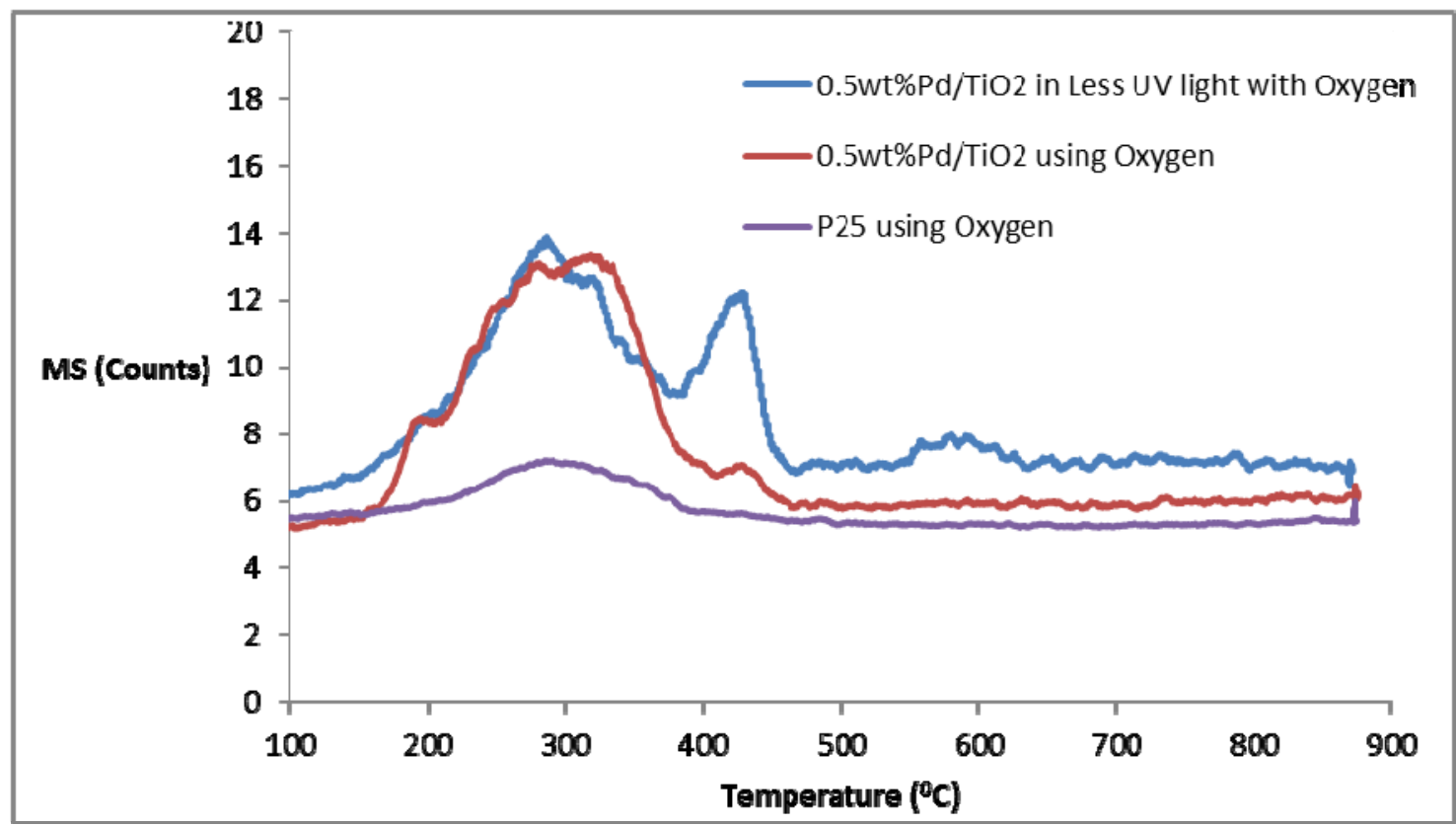

Figure S5. Temperature programmed oxidation of catalysts showing evolution of $\mathrm{CO}_{2}$ as a function of temperature. 

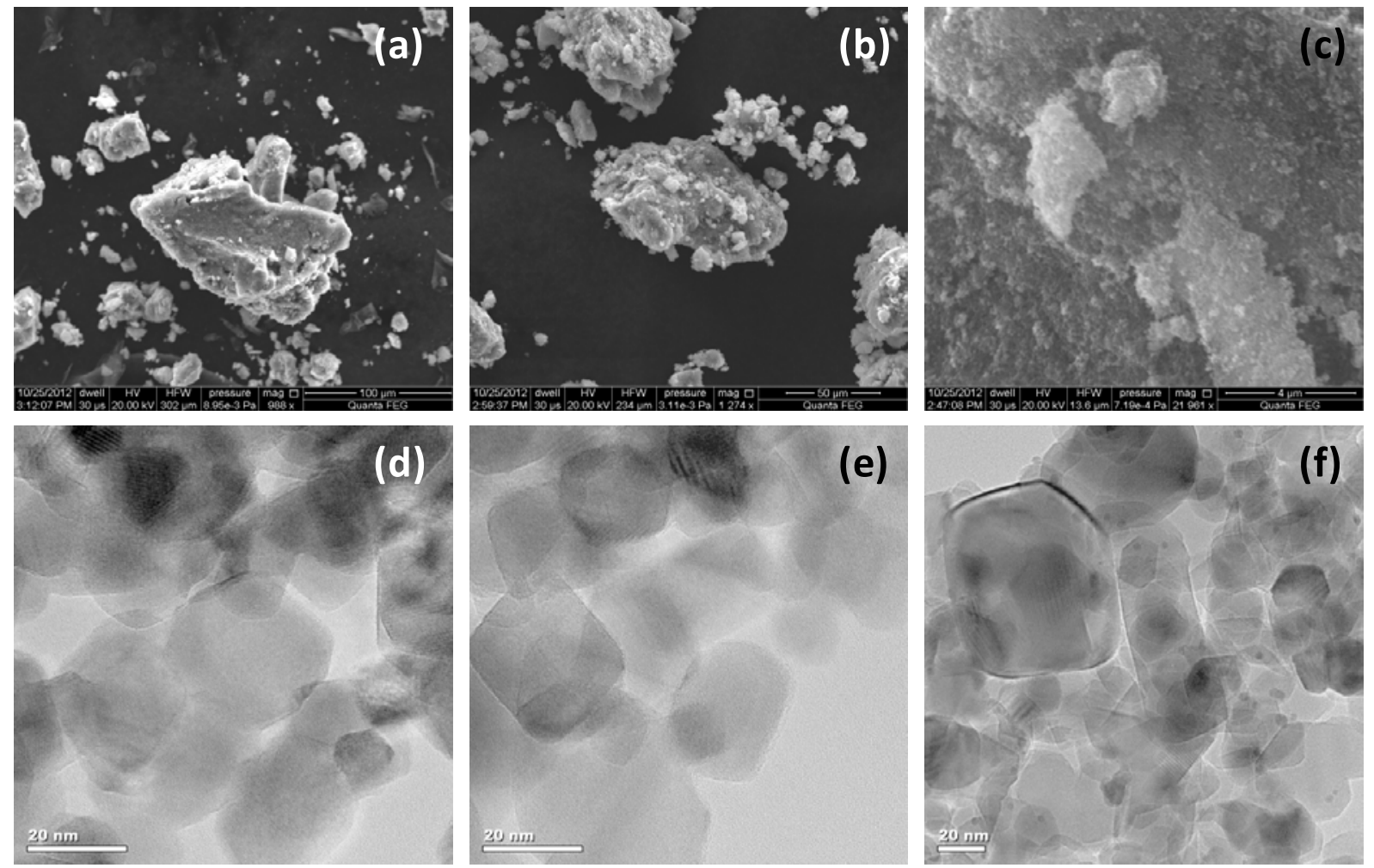

Figure S6. SEM images of (a) $\mathrm{Au} / \mathrm{TiO}_{2}$, (b) $\mathrm{Pd} / \mathrm{TiO}_{2}$, (c) $\mathrm{Au}-\mathrm{Pd} / \mathrm{TiO}_{2}$ and $\mathrm{TEM}$ images of (d) $\mathrm{Au} / \mathrm{TiO}_{2},(\mathrm{e}) \mathrm{Pd} / \mathrm{TiO}_{2}$, (f) $\mathrm{Au}-\mathrm{Pd} / \mathrm{TiO}_{2}$ 
$\mathrm{Ti} K \alpha 1$

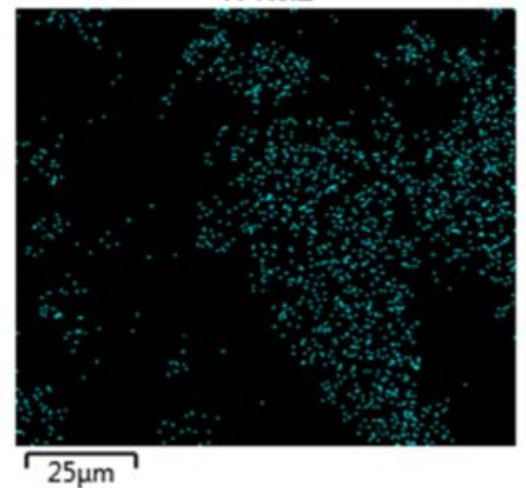

$\mathrm{O} K \alpha 1$

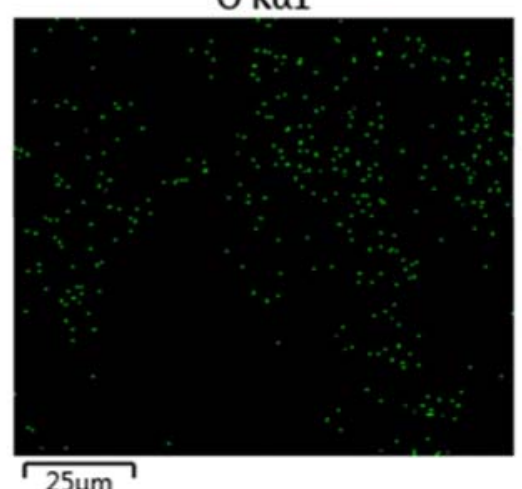

$\longdiv { 2 5 u m }$
$\operatorname{Pd} \operatorname{L} \alpha 1$

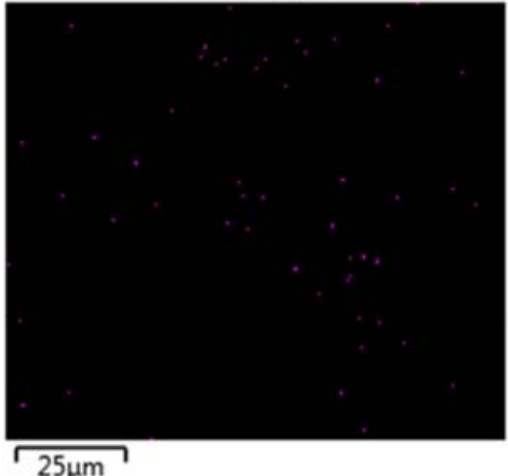

C Ka1_2

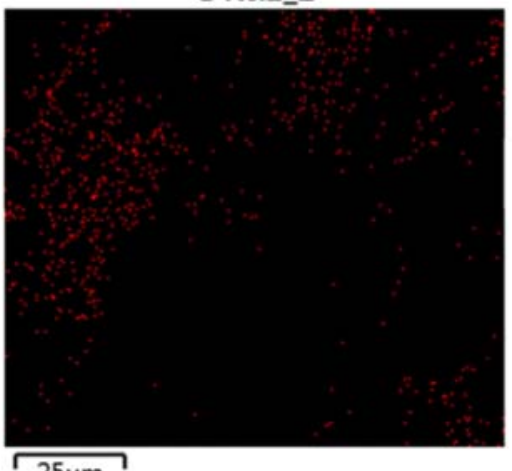

$\longdiv { 2 5 u m }$

Figure S7. SEM EDS Mapping of $\mathrm{Pd} / \mathrm{TiO}_{2}$ catalyst

\section{Table S1.}

Carbonaceous species adsorbed on the catalyst surface

\begin{tabular}{lcc}
\hline Catalyst & $\begin{array}{c}\text { Desorption } \\
\text { Temperature } \\
\left({ }^{\circ} \mathrm{C}\right)\end{array}$ & $\begin{array}{c}\text { Carbonaceous species, } \\
\text { Weight } \%\end{array}$ \\
\hline $\mathrm{TiO}_{2} \mathrm{P} 25$ with Oxygen & 285 & 33.6 \\
$0.5 \mathrm{wt} \% \mathrm{Pd} / \mathrm{TiO}_{2}$ with Oxygen & 300 & 47.9 \\
$0.5 \mathrm{wt} \% \mathrm{Pd} / \mathrm{TiO}_{2}$ with less UV light & 314 & 78.1 \\
\hline
\end{tabular}

